\title{
UMA ETNOGRAFIA DAS IMPLICAÇÕES DE PODER NO TERRITÓRIO DAS INSTALAÇÕES DE TRABALHADORES TERCEIRIZADOS NA UNIVERSIDADE FEDERAL DO ABC
}

\author{
Matheus Graciosi ${ }^{1}$
}

\begin{abstract}
Resumo
O presente artigo trata de um relato etnográfico e tem como objetivo analisar, a partir de pesquisas de campo e discussões conceituais, como o território das instalações de trabalhadores terceirizados de obras, na Universidade Federal do ABC, expressa essas dinâmicas. Para tanto, recorreu-se ao uso da análise conceitual de Claude Raffestin, da transformação do espaço em território. Nota-se um distanciamento simbólico muito grande, em contraponto com uma proximidade espacial, entre a comunidade acadêmica representada pelos alunos, técnicos administrativos e professores e os trabalhadores dessas instalações. E como resultados surgiram reflexões a partir de como esse distanciamento é produzido e mantido a partir de práticas cotidianas e institucionais.
\end{abstract}

Palavras-chaves: etnografia, território, terceirização.

\section{Abstract}

This paper is an ethnography essay and its main goal is to understand from field research and conceptual discussions how the territory of outsourced workers' at Federal University of ABC express its dynamics. Therefore it was used the Claude Raffestin's conceptual analysis of transformation of space into territory. It is possible to see a huge symbolical distancing standing in opposition a spacial proximity between the academic community represented by the students, administrative technicians and professors and the workers of this installation. As results, some considerations emerged about how daily and institutional practices produce and maintain this distancing.

Keywords: ethnography, territory, outsourcing.

\footnotetext{
${ }^{1}$ Universidade Federal do ABC. E-mail: matheusgraciosi@gmail.com. 
Local de estudo no campus de São Bernardo do Campo, visto da escadaria do terceiro andar do Bloco Delta.

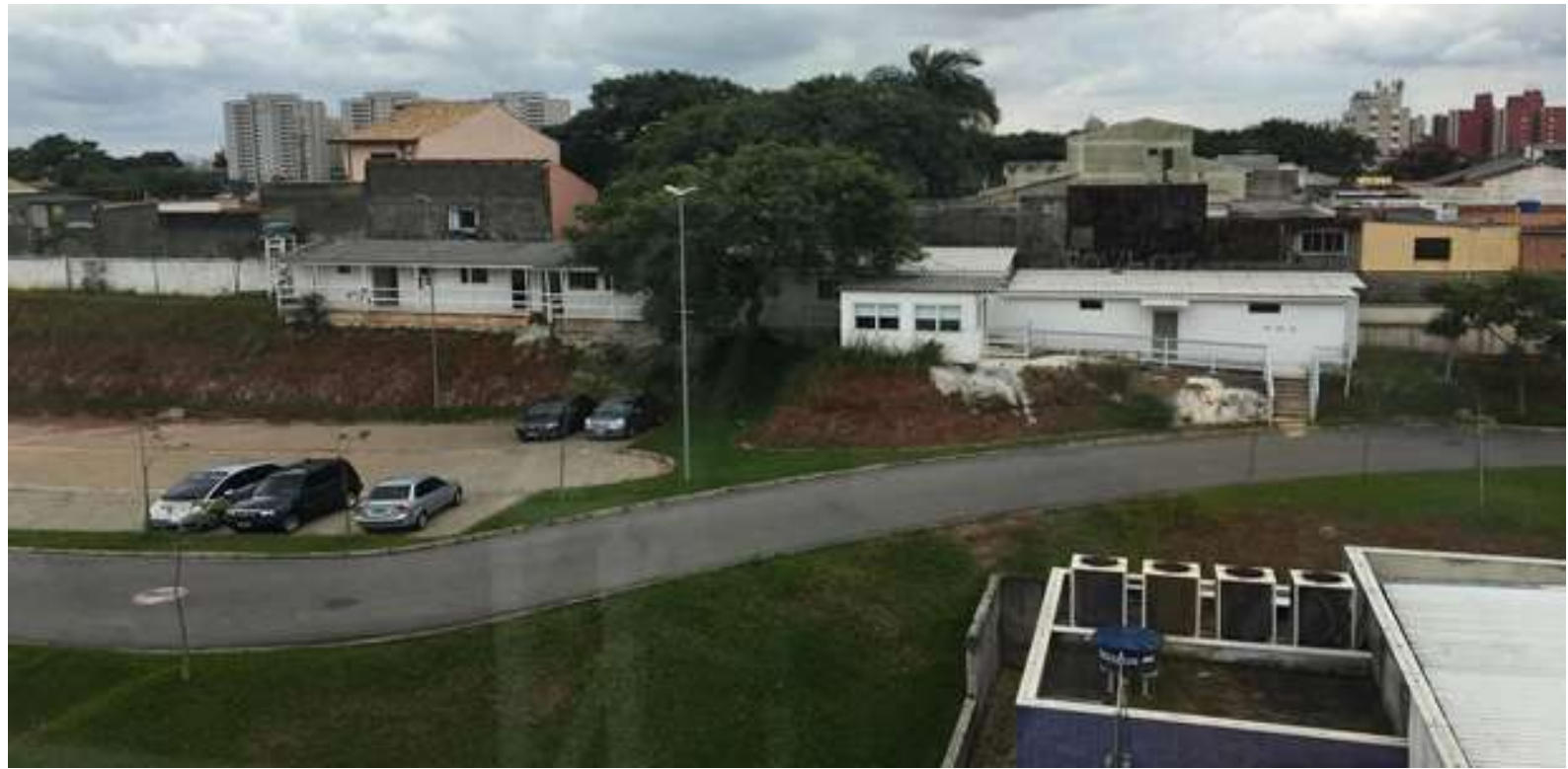

Fonte: do autor.

No campus de São Bernardo do Campo, da Universidade Federal do ABC (UFABC), existe um pequeno aglomerado de "cômodos", com uma morfologia que causa estranhamento por sua organicidade e ar de improviso, em uma região "periférica" quando em comparação com a centralidade existente a partir dos fluxos entre blocos de aulas e laboratórios existentes no campus.

Esse aglomerado está em cima de um morro e é aparente a contenção feita de maneira bem desleixada com cimento, além de ser perceptível uma escada de acesso - para esses cômodos que aparentam ter diferentes usos. Essa dependência levantava especulações esporádicas - quando de repente notávamos sua existência para além da "batida de olho" -, desde 2015, ano em que ingressei como aluno do Bacharelado em Ciências e Humanidades, na UFABC.

Em aula, foi um dos primeiros objetos de estudo que surgiram em minha mente, justamente por eu já ter tido essa curiosidade, mas nunca ter ido procurar saber a respeito. Em grupo, decidimos adotar como nosso local de estudo e investigação.

Os "rumores" iniciais a respeito daquele local tinham como conteúdo principal o fato de que os trabalhadores das obras da UFABC dormiam ali. Na minha cabeça, as perguntas e justificativas para a escolha do campo já estavam formadas, a dúvida residia entre: as condições de trabalho e pagamento são tão precárias, que os trabalhadores não tinham 
condições de voltar todos os dias para casa, ou então, mesmo que tivessem dinheiro para isso, moravam tão longe que compensava passar a semana nesse "alojamento".

Com isso em mente, meu grupo de trabalho e eu (composto por outras três integrantes) começamos a elaborar estratégias de aproximação. Tive a ideia de conversar com dois seguranças da universidade que tenho mais contato, Denis e Claudia (nomes fíctícios). A ideia era que, se alguém soubesse de algo concreto a respeito, seria Denis, pois é uma das pessoas que mais sabe sobre o funcionamento da UFABC. Fizemos uma aproximação e ensaio de conversa com Claudia, questionando se ela sabia onde estava o Denis, que no mesmo momento chegou na sala em que Claudia e eu estávamos.

Conversamos por cerca de trinta minutos, o que foi muito importante para o desenvolvimento deste estudo. A partir dessa conversa, fomos capazes de adequar as nossas expectativas e idealizações a respeito do que seriam aquelas dependências. Esse ajuste foi fundamental para avançarmos na preparação do que seriam nossas entrevistas e como começaríamos, de fato, a abordar as pessoas que utilizavam daquele espaço.

A conversa com Denis mostrou que muito do que tínhamos como premissas para a elaboração do estudo etnográfico não se encaixava com a realidade daqueles trabalhadores. Nesse sentido, decidimos que nosso foco com esse estudo etnográfico seria entender as pessoas que faziam uso daquele espaço e constituem um território. Aqui, acredito que vale um adendo para uma explanação conceitual a respeito da diferenciação entre espaço e território, principalmente porque essas questões se mostraram importantes ao decorrer do estudo etnográfico pretendido.

O conceito de território é alvo de discussões diversas inspiradoras de livros e artigos científicos que buscassem explorar suas possibilidades de significação desde a década de 1950. Da filosofia até a geografia, o território vem sendo abordado em diversas dimensões, porém eu trago a definição de Raffestin (1993), não por ela esgotar a discussão, mas sim por introduzir elementos que contribuem para as problemáticas que esse estudo indicou:

um espaço onde se projetou um trabalho, seja energia e informação, e que, por consequência, revela relações marcadas pelo poder. (...) o território se apoia no espaço, mas não é o espaço. É uma produção a partir do espaço. Ora, a produção, por causa de todas as relações que envolve, se inscreve num campo de poder (Raffestin, 1993, p. 144)

O mais importante para mantermos da definição acima, acredito ser a questão da construção do território a partir do espaço, enquanto algo complexo que é produto das relações sociais e de poder expressas, em combinação com os elementos materiais existentes e indo além, reforçando o quão dinâmicas e suscetíveis as transformações do território são. 
Dentro do campus, e de certa forma, nos rigores dos postulados da matemática e da lógica, contido nesse território, a impressão cotidiana é de não pertencimento, um certo distanciamento. Aparentemente, a melhor maneira de atingir esses objetivos seria através de entrevistas com os trabalhadores, e a partir dali ver onde seríamos levados.

Com isso em mente, decidimos fazer nossa primeira aproximação para entrevistas. O que pretendíamos como entrevista se transformou em um momento turbulento e caótico, no qual foi possível realizar uma breve conversa com um dos funcionários. Para assegurar uma amostra da complexidade de sensações e ações realizadas naquele breve período de tempo, me reservo no direito de descrever integralmente o relato da conversa realizada, abaixo:

Nos reunimos na quarta-feira, após o nosso horário de almoço, para traçarmos a estratégia de como seria o campo, e consequentemente as entrevistas que gostaríamos de realizar. Já vínhamos conversando sobre isso há um tempo durante as aulas, porém o dia marcado para concretizar tinha chegado, a hora marcada para isso estava chegando e a pressão era bastante grande.

O grupo todo se reuniu no bloco Alfa 2 e decidimos de uma vez por todas ir até a área do nosso estudo de campo. Cruzamos o campus a caminho do estacionamento, cruzamos o estacionamento e enfim chegamos no pé da escada. Permanecemos ali por cerca de 1 minuto inteiro, tentando enxergar alguma coisa, pensando (inclusive em voz alta) se deveríamos subir ou não.

De repente, quando percebemos, auma das integrantes da equipe pula na escada e começa a subir. Todo o restante do grupo ficou sem reação por cerca de 3 segundos e resolvemos segui-la. A barreira de decisão entre o entrar ou não naquele território tão discutido isoladamente por nós, por tanto tempo, havia rompido. Os primeiros passos na escada foram acompanhados de grande palpitação. Será que estamos fazendo algo errado? Tudo que planejamos para o campo, ao longo de várias semanas em sala de aula, não tinha a capacidade de se concretizar. Não estávamos preparados para lidar com todas as emoções existentes a partir de uma simples subida na escada.

Após finalizarmos os degraus, a mesma integrante que iniciou a subida continuou em frente, e agora, uma vez que já havíamos rompido a barreira psicológica que enxergávamos antes, era o momento oportuno de entendermos tudo que estava ao nosso redor, com uma sensação de que a qualquer momento isso poderia acabar.

Cada janela que passávamos e dentro estava vazio representava um alívio imenso e uma chance maior de olharmos com muita atenção as dependências que estávamos fitando à 
distância já fazia mais de um mês. Era um momento surreal de confronto entre todas as idealizações já feitas e a simplicidade dos cômodos e suas aparentes utilidades cotidianas.

O primeiro cômodo que passamos foi o vestiário que tinha a porta fechada. Em seguida, do nosso lado esquerdo estava a sala de engenheiros, aquela com ar condicionado, e todas as cortinas, além da porta, estavam fechadas. Seguimos na passarela levemente desnivelada e o próximo cômodo à direita era o que parecia ser o refeitório. Cerca de 30 cadeiras estruturadas em dois móveis, daquelas de refeitório, podiam ser vistas e estavam vazias; no mesmo cômodo e mais adiante, podia ser visto uma espécie de forno desligado.

Até o momento em que estávamos no refeitório, a distribuição da equipe se dava de modo que em linha reta, 2 dos integrantes estavam mais à frente e dois mais para trás. Nisso, as duas de trás alegam quase gritando por não conseguir controlar a emoção oriunda daquele evento: "TEM ALGUÉM VINDO!"

E de repente, todos surtamos, sem nenhuma explicação plausível. Eu e Mayara que estávamos mais para frente decidimos continuar caminhando, agora mais rápido, até chegarmos aos banheiros que representavam os últimos cômodos da instalação. Eu repetia com certa frequência, com um tom elevado, mas daqueles que você tenta falar baixo: continua olhando!! Olha tudo!!!

Depois de um tempo para absorver toda a situação inevitável que seria o encontro com o homem que se aproximava, resolvemos recuar um pouco e ir ao seu encontro. A territorialização de nosso encontro foi bastante simbólica: estávamos no meio do caminho entre o início e o fim da extensão da instalação que abrigava todos os cômodos que tentávamos ver e entender.

Quando estávamos todos no mesmo local, com a leitura corporal indicando que era o momento de conversarmos, antes mesmo dele falar qualquer coisa, uma das integrantes da equipe começou explicando que estávamos fazendo uma disciplina na faculdade e que tínhamos escolhido essa dependência para entender do que se tratava.

O homem então se dispôs a explicar que eles trabalham como terceirizados com a universidade. Segundo ele, existem pendências de execução de obras no bloco Zeta e também no estacionamento, que se encontra suspenso por conta de uma auditoria interna da universidade.

Perguntei então se o pessoal que trabalha nessas obras que ele havia descrito utilizam das dependências que nos encontrávamos e ele então responde que "justamente”, indicando 
que alí existe um vestiário, um refeitório, uma copa, a sala dele (que não conseguimos entender qual seria), sala de engenheiros e dois banheiros.

Perguntamos quem utiliza do espaço, e segundo ele, só estava sendo utilizado por ele e um engenheiro, por conta da interdição das obras. Porém, além disso, ele também informa que de 30 a 40 pessoas utilizam.

Seguido de longos segundos em silêncio e sem muita capacidade de reação da nossa parte, alguém questiona se podemos andar pelas dependências e ver com mais detalhe $e$ calma. Ele então diz que podemos sim, com um aparente incômodo em relação à nossa presença. No momento isso pareceu uma boa estratégia para amenizar o clima de tensão existente entre nós e ele.

De maneira descontraída, afirmamos que já estávamos dando uma olhada mesmo sem autorização e nos desculpamos. Ele então retoma que estava almoçando no carro e viu que estávamos subindo a escada e entrando nas instalações, o que despertou nele a necessidade de ver do que se tratava. Nesse momento pareceu ficar explícito o motivo do aparente incômodo.

Essa informação foi muito interessante porque depois de um tempo percebemos que durante o primeiro longo minuto de indecisão à beira da escada, foi integralmente observado por ele. E isso foi bastante constrangedor, além de possivelmente significativo para a maneira como ele passara a nos enxergar.

Em seguida, após esse momento de descontração, aproveitamos para fazer mais perguntas sobre os aspectos físicos das instalações. Questionamos se a construção dos cômodos era responsabilidade dele(s) e ele afirmou que foi entregue pronto pela universidade, com uma parte mais consolidada e uma bem precária em madeira,que eles construíram em alvenaria e com revestimento externo.

Nos despedimos depois de quase três minutos de conversa e demos mais uma olhada. Um sentimento coletivo de frustração pairava sobre nós. Enquanto olhávamos as instalações, agora com o aval dele, cochichamos sobre a necessidade de perguntarmos mais, de sabermos mais coisas, mas não sabíamos como reagir. A pouca receptividade por conta dele, e nossa postura coletiva se mostrou um entrave grande em conseguirmos maiores informações, mas até aquele momento, a sensação é que não tínhamos mais como forçar a situação.

Nesse momento, vinha à minha cabeça algo que li em uma pesquisa etnográfica que resultou em uma dissertação de mestrado sobre trabalhadoras e suas jornadas, a partir da ótica da terceirização em um órgão público federal, em que a autora disse: "Em alguns 
momentos, até poderia ter conquistado uma entrevista ou outra, mas não acredito em estabelecer relação tão vertical em campo." (Chagas, 2014, p. 20). A situação tinha muita similaridade, desde a natureza federativa, até a terceirização do trabalho, mesmo que o recorte da autora em questão seja para trabalhadoras da limpeza, enquanto a nossa situação lidava com uma espécie de administrador.

Enquanto retornamos para a ponta da escada, a integrante da equipe que se encontrava como última da fileira da equipe de quatro pessoas, pergunta: Qual o seu nome mesmo? E ele responde prontamente: Jeferson (nome fictício). O nível de tensão nessa breve conversa era tamanho que apenas no último segundo de contato possível, descobrimos seu nome, ao mesmo tempo que não descobrimos nem sua função.

Processar todos esses acontecimentos, que não duraram mais que 5 minutos, foi uma tarefa difícil, mas depois desse momento de contemplação e reflexão, percebemos que o problema de pesquisa agora era outro. E fiel à experiência da etnografia, a organicidade e singularidade daquela interação com Jeferson determinaram os caminhos finais do nosso estudo.

Os incômodos superaram as expectativas pessimistas que pairavam sob a minha cabeça já fazia um tempo - porém de uma maneira não necessariamente negativa. Esse pequeno momento foi capaz de explicitar muitas relações já moldadas e reforçadas diariamente: a posição implícita que nos enxergamos (ou nos fazemos enxergar).

Partimos de universos bastante distintos, e consequentemente, posições de poder muito diferentes. De um lado, estudantes de uma Universidade Federal na casa dos 20 anos, barulhentos e visivelmente estranhos, que tem com esse espaço do campus uma relação cotidiana bastante frequente, intensa e ampla; do outro, um trabalhador terceirizado, estando naquele espaço há pouco mais de um ano, com certezas mais fracas a respeito de sua permanência em um horizonte temporal de cinco anos - dado o contexto político-social de precarização do trabalho -, que tem como único espaço destinado exclusivamente a ele, o local que escolhemos como objeto de estudo.

Com esse contexto, naquele momento, estávamos invadindo um espaço que não era, $a$ priori, destinado a nós enquanto estudantes - possivelmente um dos poucos em todo o campus. E a partir dessa sensação ficou o questionamento bem marcado: como se dá essa relação a partir da perspectiva da outra ponta (representada pelo Jeferson)?

Muito provavelmente a sensação deve ser similar, se por um acaso, o Jeferson entrasse em uma sala de aula e de repente começasse a entrar alunos ou professores. A partir desse 
ponto já estamos entrando em um campo especulativo, assim como grande parte das questões que extrapolam a descrição da minha subjetividade.

Uma maneira de sair do campo especulativo e trazer como um elemento da subjetividade de Jeferson a respeito das questões que nos colocamos, seria fazermos essas perguntas para ele. Mas justamente por conta da experiência que tivemos, transpor da teoria/papel e concretizar na realidade esse tipo de pergunta, com um teor tão pessoal, simplesmente não pareceu possível. Não havia aberturas.

Insatisfeitos com o que tínhamos enquanto material para responder nossas questões e problemas pontuados pelo estudo etnográfico, decidimos realizar entrevistas com pessoas que tinham vínculos com a universidade sem ser terceirizado. A intenção era, naquele momento, entender se a sensação de afastamento simbólico que sentimos se manifestava, em certa medida, com pessoas que tinham uma relação similar à nossa, em relação àquela instalação.

Conversamos individualmente, às vezes em duplas, e uma das vezes a equipe toda com alunos, professores e técnicos administrativos. Porém aqui eu trago o registro de uma Técnica-Administrativa, Jéssica, que se mostrou importante para nosso estudo, principalmente por conta do tempo em que ela já estava na universidade (que era há mais de 5 anos). Essa informação era interessante como um bônus, para nós, porque era tempo a mais que todos da equipe, que ingressou em 2015.

As conversas descontraídas tinham como conteúdo questionamentos a respeito da relação que essas pessoas tinham com as pessoas que utilizavam daquele espaço (referente ao nosso local de estudo) e as respostas eram bem similares, orientadas pelo não conhecimento do que seria o local e quem seriam essas pessoas que usavam do espaço.

Esse terceiro momento de entrevistas/conversas realizadas fez com que refletíssemos a respeito do quão longe avançaríamos para este estudo. Em certa medida, tudo isso já era suficiente justamente por explicitar de maneira tão intensa, por um lado um distanciamento simbólico muito grande, em contraponto com uma proximidade espacial (no sentido de todos esses elementos espaciais estarem circundado pelo campus de São Bernardo do Campo); e por outro, um "choque entre esses mundos" quando colocados em contato, com um estranhamento nítido do nosso lado, e uma sensação de desconfiança e desconforto com a nossa presença.

O que fica a partir dessa experiência é o questionamento a respeito de como esse distanciamento é produzido e mantido. Como as práticas cotidianas dos sujeitos que compõem esse território (sujeitos esses indicados a partir da tentativa de enquadramento de todos os indivíduos e grupos sociais que se relacionam com o espaço do câmpus de São Bernardo do 
Campo) reforçam essas condicionantes sociais, lembrando que o território não é estático e está em constante alteração.

A constante transformação do espaço em território, como Raffestin trouxe, enquanto um processo constante, salta aos olhos quando penso no campo de estudo que escolhi junto às outras integrantes do meu grupo. Desde a localização, dentro do câmpus, totalmente abjeta de qualquer circulação cotidiana que não seja necessariamente alí - por vezes se confundindo com as casas do outro lado da rua -, até as condições da instalação, com alguns materiais improvisados, uma contenção de cimento com pouco grau de acabamento. Todos esses elementos físicos se relacionam com elementos simbólicos e imateriais de poder e relações sociais ali - e fora dali - existentes, e perpetuados cotidianamente, de modo que o estranhamento resultante da tentativa de aproximação se torna compreensível, mas ainda assim intrigante. 


\section{Referências Bibliográficas}

CHAGAS, Herika C. A. Trabalhadoras e suas jornadas: reflexões sobre a terceirização em um órgão público federal. 2014. 111f. Dissertação (Mestrado em Antropologia Social) Universidade de Brasília, Brasília, 2014.

RAFFESTIN, Claude. Por uma geografia do poder. Tradução de Maria Cecília França. São Paulo: Ática, 1993. 